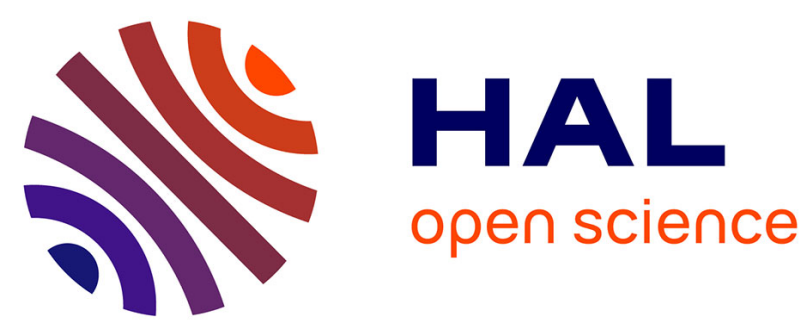

\title{
Lack of DNA helicase Pif1 disrupts zinc and iron homeostasis in yeast
}

\author{
María Guirola, Lina Barreto, Ayelen Pagani, Miriam Romagosa, Antonio \\ Casamayor, Silvia Atrian, Joaquin Ariño
}

\section{- To cite this version:}

María Guirola, Lina Barreto, Ayelen Pagani, Miriam Romagosa, Antonio Casamayor, et al.. Lack of DNA helicase Pif1 disrupts zinc and iron homeostasis in yeast. Biochemical Journal, 2010, 432 (3), pp.595-605. 10.1042/BJ20101032 . hal-00539723

\section{HAL Id: hal-00539723 \\ https://hal.science/hal-00539723}

Submitted on 25 Nov 2010

HAL is a multi-disciplinary open access archive for the deposit and dissemination of scientific research documents, whether they are published or not. The documents may come from teaching and research institutions in France or abroad, or from public or private research centers.
L'archive ouverte pluridisciplinaire HAL, est destinée au dépôt et à la diffusion de documents scientifiques de niveau recherche, publiés ou non, émanant des établissements d'enseignement et de recherche français ou étrangers, des laboratoires publics ou privés. 


\title{
Lack of DNA helicase Pif1 disrupts zinc and iron homeostasis in yeast
}

\author{
María Guirola ${ }^{1,{ }^{*},}$ Lina Barreto ${ }^{2, *}$, Ayelen Pagani ${ }^{1}$, Miriam Romagosa ${ }^{1}$, \\ Antonio Casamayor ${ }^{2}$, Silvia Atrian ${ }^{1, \S}$ and Joaquín Ariño ${ }^{2, \S, \pi}$ \\ ${ }^{1}$ Departament de Genètica and Institut de Biomedicina, Universitat de \\ Barcelona, Barcelona \\ ${ }^{2}$ Departament de Bioquímica i Biologia Molecular and Institut de Biotecnologia i \\ Biomedicina, Universitat Autónoma de Barcelona, Bellaterra 08193, Barcelona, \\ Spain
}

Running Title: zinc and iron homeostasis in pif1 mutants

Abbreviations: BPS, Bathophenantroline disulfonic acid;

${ }^{*}$ Both authors contributed equally to this work
${ }^{\S}$ Co-last authors

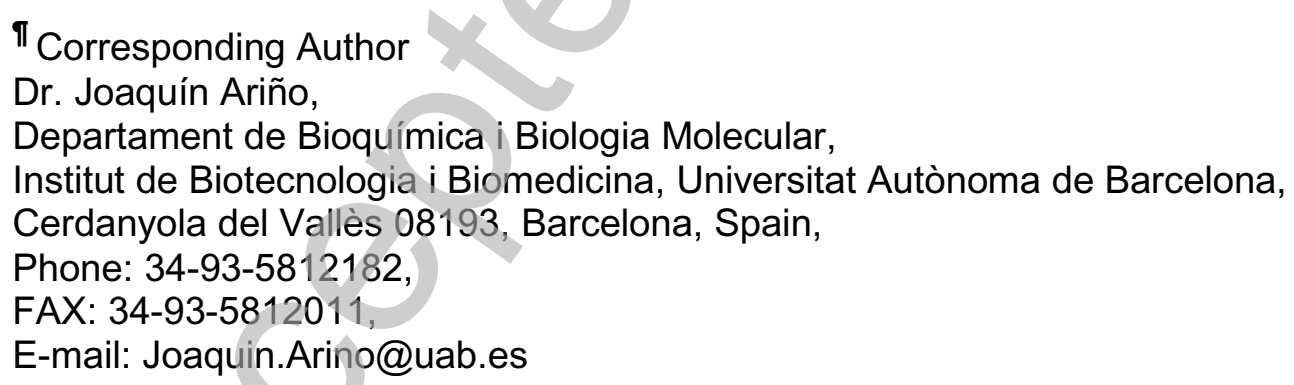




\section{Summary}

The Saccharomyces cerevisiae gene PIF1 encodes a conserved eukaryotic DNA helicase required for both mitochondrial and nuclear DNA integrity. Our previous work revealed that a pif1 $\Delta$ strain is tolerant to zinc overload. We demonstrate here that this effect is independent of the Pif1 helicase activity and is only observed when the protein is absent from the mitochondria. pif1 cells accumulate abnormal amounts of mitochondrial zinc and iron. Transcriptional profiling reveals that pif1 cells under standard growth conditions overexpress aconitase-related genes. When exposed to zinc, pif1 cells show lower induction of genes encoding iron (siderophores) transporters and higher expression of genes related to oxidative stress responses than wild type cells. Coincidently, pif1 mutants are less prone to zinc-induced oxidative stress and display a higher reduced/oxidized glutathione ratio. Strikingly, although pif1 cells contain normal amounts of the Aco1 protein, they completely lack aconitase activity. Loss of Aco1 activity is also observed when the cell expresses a non-mitochondrially targeted form of Pif1. We postulate that lack of Pif1 forces aconitase to play its DNA protective role as nucleoid protein and that this would trigger a domino effect on iron homeostasis resulting in increased zinc tolerance.

Key words: zinc homeostasis, iron homeostasis, Pif1, aconitase, Saccharomyces 


\section{INTRODUCTION}

Zinc is an essential metal for all organisms, participating in the structure and/or function of many proteins. Although redox inactive, zinc excess is deleterious to cells. The budding yeast Saccharomyces cerevisiae is not an exception and homeostatic mechanisms exist that ensure cellular responses to both zinc deficiency and surplus. The cellular response to zinc deficiency has been thoroughly characterized, (cf. recent revision [1]). The vacuole has been identified as the storage system for zinc [2-4], but beyond that little is known about the cellular mechanisms that are induced by or regulate zinc excess [5].

Recently, our group reported a genome-wide study of the molecular effects caused by high zinc levels in S. cerevisiae, by combining a screen of the haploid deletion library with transcriptomic profiling [6]. We confirmed the requirement of numerous chaperones for proper protein folding or targeting to vacuole and mitochondria. Additionally, several genes involved in stress response (mainly oxidative), sulphur metabolism, as well as components of the iron regulon were identified as crucial components of cellular resistance to high zinc. We also showed that exposure to high zinc generates reactive oxygen species, which paradoxically is exactly the same effect produced by zinc starvation [7]. Significantly, zinc excess results in a concomitant decrease of intracellular iron levels, as well as aconitase (Aco1) and cytochrome $c$ activities in stationary-phase cultures. These results suggest that high zinc may alter the assembly and/or function of iron-sulfur containing proteins, thus establishing a link between zinc, iron and sulfur metabolism.

Our screen highlighted a unique deletion mutant exhibiting a clear high zinctolerance phenotype. In zinc supplemented medium cells lacking the PIF1 gene grew much better than wild type cells. Pif1 is a DNA helicase, conserved from yeast to humans [8]; reviewed in [9]. In yeast, Pif1 has been associated to the maintenance of mitochondrial DNA (mtDNA) [10], as pif1 mutants tend to lose their mtDNA owing to their incapacity to efficiently perform mtDNA repair and recombination [11;12]. These deficiencies lead to a temperature-dependent petite phenotype [13]. A nuclear role as inhibitor of telomere elongation by displacing telomerase from its substrate $[14 ; 15]$ was also proposed for Pif1 [16].

The role of Pif1 in DNA maintenance provided no clues to explain the increase in zinc tolerance observed for the pif1 $\Delta$ mutation. However, the fact that aconitase has been shown to be essential for mtDNA maintenance independent of its catalytic activity [17], together with a recent report showing that overexpression of ACO1 suppressed mtDNA instability in the pif1 $\triangle$ mutant [18], suggested a functional link between both proteins. Because of the relevant role of aconitase in metal homeostasis, we decided to re-examine the effect of pif1 deletion on the cellular response to zinc overload, thus expanding on our studies on zinc homeostasis in wild type cells [6]. As a result, we report here that zinc and iron homeostasis is altered in pif1 mutants and that these cells completely lack aconitase activity. It is known that this Fe-S cluster-containing enzyme acts as sensor of cellular iron status [19]. This fact, together with the strong epistasis of ACO1 with PIF1 allow postulating that lack of Pif1 may force Aco1 to strengthen its mtDNA protective role as nucleoid protein, with loss of its enzymatic activity, which would trigger a domino effect on iron homeostasis resulting in increased zinc tolerance. Therefore, the multifunctional nature of yeast aconitase [20;21] would be at the crossroad of the pleiotropic effect of PIF1 deletion. 


\section{EXPERIMENTAL}

\section{Yeast strains and culture conditions}

Yeast strains used in this work are described in Table 1. Growth tests on agar plates (dot tests) were carried out by spotting $3 \mu \mathrm{l}$ of culture dilutions (starting at $\mathrm{OD}_{600}$ 0.05 ) and incubating at $28{ }^{\circ} \mathrm{C}$ for the indicated times. Growth tests in liquid cultures were carried out as follows. Overnight cultures were diluted in $310 \mu \mathrm{l}$ of YPD up to $\mathrm{OD}_{600} 0.01$ in 96 -well plates with or without the appropriate additions (i.e. $\mathrm{ZnCl}$ ) and growth resumed at $28^{\circ} \mathrm{C}$ for $24-48 \mathrm{~h}$. The OD at $595 \mathrm{~nm}$ was determined in a Thermo Multiskan Ascent 96-well reader.

\section{Cell culture conditions for metal accumulation measurements}

S. cerevisiae strain BY4741 and its derivative mutant pif1 $\triangle$ were grown in YPD media until exponential phase $\left(A_{600} 0.6\right)$. Growth was resumed in the absence or the presence of $5 \mathrm{mM} \mathrm{ZnCl}_{2}$ for $24 \mathrm{~h}$, when stationary phase $\left(A_{600} \sim 2.5-3.0\right.$ depending on the zinc concentration) was reached. Samples containing 40 and $80 A_{600}$ of cells (for total metal content and mitochondrial metal content, respectively) were taken at the moment of metal addition and $24 \mathrm{~h}$ after.

\section{Total and mitochondrial metal content measurement}

Cellular metal content was measured by Inductively Coupled Plasma-Atomic Emission Spectrometry in a Polyscan 61E apparatus (Thermo Jarrell Ash), as described in [6]. Mitochondria were isolated using a Yeast Mitochondria Isolation Kit (MITOISO3, Sigma Aldrich, USA). The quality of the isolation process was evaluated by Western Blotting using an antibody rabbit polyclonal antiserum (1:8000 dilution) developed against cytochrome $C$ (Cyt1, a kind gift of D. Pain) and to vacuolar carboxypeptidase $Y$ (dilution: 1:7500, a generous gift of $\mathrm{M}$. Geli). This analysis indicated that mitochondrial preparations were devoid of vacuolar contamination (see Supplemental Figure 1). Metal measurements were made as described for cellular content, except that Inductively Coupled Plasma-Mass Spectrometry was used for determinations using an Eland-6000 apparatus (Perkin-Elmer).

\section{RNA purification, cDNA Synthesis and DNA microarray experiments}

For RNA purification $25 \mathrm{ml}$ of yeast cultures were grown at $28{ }^{\circ} \mathrm{C}$ in YPD medium until $A_{660}$ 0.6. Yeast cells were cultured for one additional hour, in the presence or absence of $5 \mathrm{mM} \mathrm{ZnCl}$. Cells were harvested by centrifugation and washed with cold water. Dried cell pellets were kept at $-80{ }^{\circ} \mathrm{C}$ until RNA purification. Total RNA was purified using the RiboPure-Yeast kit (Ambion) following the manufacturer's instructions. RNA quality was assessed by electrophoresis in denaturing $0.8 \%$ agarose gel and quantified by measuring $A_{260}$ in a BioPhotometer (Eppendorf).

Transcriptional analyses were performed using DNA microarrays containing PCR-amplified fragments from $6014 \mathrm{~S}$. cerevisiae ORFs [22;23] as described previously [6]. For each experimental condition a dye swapping was performed. The fluorescent intensity of the spots was measured and processed using the GenePix Pro 6.0 software (Molecular Devices). Spots with either a diameter smaller than $120 \mu \mathrm{m}$, or fluorescence intensity for Cy3 and Cy5 lower than 150 units, were not considered for further analysis. A given gene was considered to be induced or repressed when the ratio between the two compared samples was higher than 1.8 or lower than 0.55 , respectively. Genes whose expression was considered changed in any of the tested mutants were selected for further analyses. The GEPAS server (http://gepas.bioinfo.cnio.es) was used to pre-process the data and to establish correlations between expression patterns [24]. Expression profile analysis of the selected genes was determined with EPCluster [25;25]. Gene Ontology analysis was performed using "GO Term Finder" tool at the SGD server 
(http://www.yeastgenome.org/). When wild type and pif1 profiles were compared, the level of Pif1 dependence for expression was set as follows: genes showing a ratio 0.67 $>X>0.50$ were considered "weakly dependent" (WD); those with a ratio $0.50>X>$ 0.25 were ranked as "strongly dependent" (SD) and those with a ratio $<0.25$ were labelled as "totally dependent" (TD). Similarly, genes induced more than 2.5 -fold in one strain and considered not induced (i.e ratio +/- zinc <1.3) in the other were also considered as totally dependent. Microarray data can be retrieved from GEO (GSE18411). Genes encoding mitochondrial proteins were extracted with the Gene Ontology Slim Mapper Tool at Saccharomyces Genome Database [26].

\section{Evaluation of ROS formation and measurement of glutathione levels}

Evaluation of ROS formation was carried out as in [6] using wild-type BY4741 cells and its isogenic derivative pif1::kanMX. $\mathrm{ZnCl}_{2}$ was added to a final concentration of $10 \mathrm{mM}$. Parallel cultures received hydrogen peroxide $5 \mathrm{mM}$. Fluorescence in each sample was calculated using the Wasabi software. Around 600 cells per condition were selected from diverse Nomarski images and the intensity of its fluorescence automatically measured from the fluorescence image. Background values were obtained from several areas devoid of cells and subtracted. The average florescence per condition was then calculated.

Glutathione levels were measured as described previously [6].

\section{Measurement of aconitase activity and protein content}

Strains were grown as for metal determination except that 20 and 25 absorbance units were collected for protein quantification and activity assay samples, respectively, and that cells were taken at stationary phase (24h). A BY4741 aco1 $\Delta$ derivative mutant (lacking the yeast mitochondrial aconitase gene) was grown under same conditions and was used as control in the aconitase protein and activity assays.

Aconitase activity was determined essentially as in [6]. The aconitase contents were measured in total cell extracts and also in mitochondrial and non-mitochondrial fractions. Total cell extract was prepared from 20 absorbance units of cells harvested, washed, resuspended in $0.1 \mathrm{ml}$ of $100 \mathrm{mM}$ Tris- $\mathrm{HCl} \mathrm{pH} \mathrm{8.0,} \mathrm{plus} 1 \mathrm{mM}$ PMSF and proteases inhibitors (Complete EDTA-free, Roche). Cells were broken with aid of glass beads. After a 15-min spin at $13,000 \mathrm{rpm}$ in a microfuge, the supernatant was separated and stored at $-20^{\circ} \mathrm{C}$. Total protein content was determined by using the Quick Start Bradford protein assay kit (Bio-Rad) with bovine serum albumin as standard.

Mitochondrial and non-mitochondrial fractions were collected following the Yeast Mitochondria Isolation Kit protocol (MITOISO3, Sigma Aldrich). The aconitase content was measured by a quantitative ELISA. Plates (IWAKI, Japan) were coated with $30 \mu \mathrm{g} / \mathrm{ml}$ of cell extract or a standard curve starting on $4 \mu \mathrm{g} / \mathrm{ml}$ of Aconitase (Aconitase from porcine heart, Sigma Aldrich, USA) in carbonate buffer. Serial dilutions were made and final volume was kept in $100 \mu \mathrm{g}$. Coating step was performed overnight at $4^{\circ} \mathrm{C}$. After they were washed with phosphate-buffered saline (PBS) containing $0.5 \%$ Tween detergent, a blocking solution of PBS containing $1 \%$ bovine serum albumin (BSA) and $0.5 \%$ Tween was added for $1 \mathrm{~h}$ at $37^{\circ} \mathrm{C}$. A rabbit polyclonal antisera to Aco1 (a kind gift of A. Dancis) was added in a final concentration of 1:10 000 and then incubated overnight at $4{ }^{\circ} \mathrm{C}$. After three washes, the plates were incubated with anti rabbit Ig G-peroxidase (GE-Amersham Biosciences) at $37^{\circ} \mathrm{C}$ for $1 \mathrm{~h}$. Finally, plates were washed once more and the substrate $\mathrm{H}_{2} \mathrm{O}_{2}(3 \%)$ and o-phenylenediamine $(0.5 \mathrm{mg} / \mathrm{mL})$ in citrate buffer $0.1 \mathrm{M}(\mathrm{pH} 5)$ was used to develop the chromogenic reaction that was chemically stopped after $15 \mathrm{~min}$. The $\mathrm{A}_{492}$ was determined in a plate reader. Aconitase concentration from the samples was calculated using the standard curve as reference. 


\section{RESULTS}

\section{Characterization of tolerance to zinc in pif1 mutants}

The isolation in our previous screen of a pif1 deletion mutant as a prominent zinc hypertolerant strain prompted us to characterize the basis for this phenotype. Increased tolerance to zinc can be observed when PIF1 is deleted in different genetic backgrounds, such as BY4741 and YPH499 (Figure 1A) or DBY746 and W303-1A (not shown). It has been established that Pif1 displays helicase activity involved in mtDNA repair and telomere length regulation. Expression of an allele carrying the K264A mutation, which generates a protein unable to effectively bind ATP and thus lacks helicase activity [14], yielded cells with a wild-type tolerance to zinc cations (Figure 1A). This observation indicates that the loss of Pif1 helicase activity was not the cause for the increased zinc tolerance of the pif1 $1 \Delta$ mutant. We then determined if the effect of Pif1 on zinc tolerance was related to its nuclear or mitochondrial localization. Two different alleles of PIF1 were expressed: pif1- $m 1$, which encodes a protein targeted to the nucleus, and pif1-m2, which produces a protein largely found in the mitochondria [16]. Expression of the nuclear-targeted version resulted in cells with zinc tolerance equivalent to that of the pif1 deletion strain, indicating that this version does not act as a wild type Pif1 on zinc tolerance (Figure 1B). In contrast, expression of pif1-m2 yielded cells clearly less tolerant to zinc than the deletion mutant. These experiments demonstrate that it is the loss of mitochondrially-localized Pif1 protein which leads to zinc hypertolerance.

\section{Effect of the pif1 mutation on total and mitochondrial zinc and iron contents.}

In our previous report [6] we demonstrated that high zinc levels disrupted iron homeostasis. Therefore, we investigated here the levels of both metals in wild-type and pif1 $\Delta$ cells growing in normal and $\mathrm{Zn}$-supplemented media. Given the importance of mitochondrial localization of Pif1 for normal zinc tolerance (Figure 1B), the level of these metals was also measured in mitochondrial extracts. Exponential cultures were grown for $24 \mathrm{~h}$ in the absence or the presence of $5 \mathrm{mM}$ zinc. At the end of the incubation in the absence of added zinc, the cellular zinc content was the same for wild type and pif1 cells. In contrast, mitochondrial zinc was significantly higher in the mutant $(2.86 \pm 0.39 \mu \mathrm{g} / \mathrm{mg}$ protein) than in the wild type strain $(0.072 \pm 0.023 \mu \mathrm{g} / \mathrm{mg}$ protein $)$ (Figure 2). The differences between wild type and pif1 cells were even more dramatic when these cells were grown in zinc-supplemented media. Total zinc content increased in both wild type and pif 1 strains, although the amount was slightly lower in the mutant strain. However, mitochondrial zinc content was dramatically increased in pif1 cells, reaching values of $8.06 \pm 0.21 \mu \mathrm{g} / \mathrm{mg}$ of protein (Figure 2). These values represents an increase of 5.7 -fold when mitochondrial/total zinc ratio is calculated. All these results highlight an unreported phenotype of mitochondrial $\mathrm{Zn}$ hyperaccumulation for pif1 cells.

Analysis of total and mitochondrial iron levels in the exponentially growing cultures revealed that the lack of Pif1 resulted in higher total cellular iron content (Figure 3). While mitochondrial iron in wild type cells was very low $(0.023 \pm 0.007$ $\mu \mathrm{g} / \mathrm{mg}$ ), it spectacularly increased in pif1 mutants (10.18 \pm 0.68$)$. After 24 -h growth in the absence of added zinc, the total iron content of pif1 cells increased. However, this increase was not observed in zinc-supplemented cells. It is worth noting that regardless of the addition of zinc to the medium, the large increase in mitochondrial iron observed in the exponentially growing pif1 mutant was not observed in stationary cells.

These results are consistent with the notion that tolerance to zinc of the pif1 mutant is based in a higher cellular content of iron. Accordingly, we observed that lack of the reductive high-affinity iron transport system, encoded by FTR1 and FET3, results in a slight but perceptible decrease in zinc tolerance (Figure 4A), a phenotype that was unnoticed in our previous genome-wide screen [6]. In contrast, as expected, deletion of a siderophore transporter-encoding gene, FIT3, has no effect, given that yeast does 
not synthesize siderophores. Interestingly, chelating iron in the medium by addition of BPS significantly reduced tolerance to zinc, not only in the wild type strain, but also the protective effect of the pif1 mutation in front of an excess of zinc. In contrast, supplementation of the medium with iron in the micromolar range further increased tolerance to zinc of both wild type cells and pif1 mutant, although for the latter the effect was rather small (Figure 4B). This suggests that the observed effects are not caused by a competitive entry of zinc and iron through the low affinity Fet 4 transporter. Overall, our results indicate that a patent deregulation of mitochondrial $\mathrm{Zn}$ and $\mathrm{Fe}$ content results from deletion of PIF1 and suggest that iron availability could be a key factor for zinc tolerance not only for wild type cells, but also constitute the basis for the observed pif1 tolerant phenotype.

\section{Transcriptomic profiles of the pif1 mutant}

Comparison of the transcriptomic profile of exponentially growing wild type and pif1 $1 \Delta$ cells on YPD revealed a relatively small number of changes. Fifty-six genes appeared induced at least 1.8-fold in the pif1 mutant (Table 2). Gene ontology analysis revealed that the induced genes included several TCA cycle-related genes, (ACO1, $A C O 2, I D H 1, I D H 2)$. In addition, other genes such as $L Y S 4$ and $L E U 1$, encoding aconitase-like, sulfur-iron cluster proteins, were also induced. Expression of diverse genes responsive to hypoxia or involved in adaptation to this condition, and of three genes encoding helicase-related activities (DSS1,DHH1, YHR218W) was also increased. Interestingly, we observed an excess of genes related to mitochondrial functions (15 genes, accounting for $27 \%$ of induced genes vs expected $16.5 \%$, see Table 2). Only 24 genes were found to be less expressed in pif1 $\Delta$ than in wild type cells, among them four related to the metabolism of Cys and Met (STR3, MET16, MUP3 and MET1).

Since mutation of PIF1 results in increased tolerance to zinc, we considered necessary to evaluate how the absence of Pif1 would affect the transcriptional changes derived of exposure to this metal. To this end, we compared the datasets presented in columns 3 and 4 in Figure 5 . We observed that exposure of wild type cells to $5 \mathrm{mM}$ zinc for 60 min resulted in increased expression of 270 genes, whereas in pif1 cells we detected 244 genes (Figure 5). Among the 240 genes induced in the wild type and with valid data for the pif1 strain, 81 were less expressed in pif1 cells. Four genes were considered totally dependent of the presence of Pif1 (TD), 19 were rated as strongly dependent (SD) and 58 were defined as weakly dependent (WD, see Experimental Procedures for definitions). Gene ontology analysis of genes induced by zinc in a Pif1dependent fashion, revealed an excess of siderophore utilization-encoding genes (i.e. FIT1, ARN1, ARN2, FIT2, FIT3, p-value $5.6 \mathrm{e}^{-06}$, see Figure 5, cluster 1).In contrast, 26 genes were more induced in pif1 cells exposed to zinc than in wild type cells under the same conditions (1 TD, 4 SD, 21 WD). Among them, an excess ( $p$-value $2.9 e^{-05}$ ) of genes induced in response to oxidative stress, such as GPX2, CTT1, TRX2, SOD1, AHP1 and TSA1, were identified (Figure 5, cluster 2).

Therefore, our data suggest that lack of Pif1 in cells subjected to a zinc overload leads to increased expression of oxidative stress response genes and decreased expression of genes encoding iron (mostly siderophores) transporters. We then evaluated the tolerance to $5 \mathrm{mM}$ zinc of 26 deletion mutants for genes classified as functionally related to oxidative stress response (FunCat 32.01.01). As shown in Supplementary Figure 2, only 4 mutants displayed altered sensitivity to Zn. Two of them, tsa1 and sod 1 were very sensitive, whereas deletion of $P R X 1$ and SOD2 yielded cells slightly tolerant to the metal. Nor these two mutant strains, neither the izh3 or izh4 mutants, previously reported as zinc-tolerant [27], were identified in our previous screen [6], probably because of their relatively slight phenotype. 


\section{pif1 cells are protected against zinc-induced oxidative stress}

Previous work showed that an excess of zinc in the medium resulted in oxidative stress [6]. As shown above, genes responsive to oxidative stress are more induced in pif1 $\Delta$ cells exposed to zinc than in wild type cells. We investigated the effect of the pif1 $\Delta$ mutation in zinc-induced ROS formation by means of fluorescent 123dihydrorhodamine staining. As shown in Figure $6 \mathrm{~A}$ and $\mathrm{B}$, fluorescence induced by treatment with $10 \mathrm{mM} \mathrm{ZnCl}$ was attenuated in the pif1 mutant, indicating a lower level of ROS. This effect was specific for zinc treatment, since ROS generation caused by exposure to $5 \mathrm{mM} \mathrm{H}_{2} \mathrm{O}_{2}$ was not decreased in pif1 $\Delta$ cells. The notion that the effect of the pif1 mutation is zinc-specific is reinforced by the observation that, while tolerant to zinc, pif1 cells are more sensitive than wild type cells to diverse oxidative agents, such as $\mathrm{H}_{2} \mathrm{O}_{2}$, menadione or diamide (Figure $6 \mathrm{C}$ ).

Exposure to zinc is known to increase the oxidized/total glutathione ratio. As shown in Figure 7, pif1 cells display lower total glutathione content both under normal or zinc-stressed conditions. Under normal growth conditions, the amount of oxidized glutathione was about 4-fold lower in pif1 cells than in the wild type strain. Exposure to $6 \mathrm{mM}$ zinc strongly increased the amount of oxidized glutathione in wild type cells but had a lesser effect in the pif1 strain. Consequently, in these conditions the reduced/oxidized glutathione ratio was about 4-fold higher in pif1 mutants than in wild type cells (Figure 7, lower panel). This would be consistent with the less intense zincinduced oxidative stress observed in pif1 cells.

\section{Mutation of PIF1 dramatically affects aconitase activity}

Previously we reported [6] a marked decrease in aconitase activity in wild type cells exposed to zinc. However, no aconitase activity was detected in extracts from the pif1 $\Delta$ strain (Figure $8 \mathrm{~A}$ ) even in the absence of added zinc, being the levels similar to those of an aco1 $\Delta$ strain, which lacks the mitochondrial aconitase gene. Aconitase activity of the K264A Pif1 mutant, devoid of helicase activity, as well as of the cells in which Pif1 was directed to the mitochondria (i.e. pif1-m2), was clearly detectable, although it was somewhat lower than in wild type cells. Conversely, those cells expressing a Pif1 version exclusively targeted to the nucleus (pif1-m1), also lack aconitase activity (Figure 8A). Therefore, the same situations that result in zinc hypertolerance also give rise to lack of aconitase activity. The effect of the absence of Pif1 on aconitase activity was confirmed in a different wild type genetic background (BY4741, Figure 8B). Interestingly, exposure to zinc slightly increased aconitase activity in pif1 $\Delta$ cells, although not to the wild type strain levels in the absence of zinc (Figure 8B). In view of the absence of aconitase activity in Pif1-deficient cells, we investigated, under the same conditions, the amount of aconitase protein and its cellular distribution. Exposure of wild type cells to zinc caused an increase in the amount of total aconitase (about 50\%), with essentially no alteration of the mitochondrial/non-mitochondrial distribution of the protein (Figure $8 \mathrm{C}$ ). Remarkably, even in the absence of aconitase activity (Figure 8A and 8B) the level of the aconitase protein in untreated pif1 $\triangle$ cells was normal and the protein was largely mitochondrial. Exposure of pif $1 \Delta$ cells to zinc caused a moderate increase in aconitase protein, similar to that observed in the wild type and a decrease in the relative amount of aconitase located in the mitochondria. In essence, our results indicate that the absence of aconitase activity in cells lacking Pif1 or unable to localize Pif1 to the mitochondria is not caused by the absence of aconitase protein, and that the pif1 mutation provokes a dramatic alteration in the intracellular distribution of aconitase. It is worth noting that deletion of aconitase results in an increase in zinc tolerance comparable to that of the pif1 mutant (Figure 8D). 


\section{DISCUSSION}

Pif1 is a conserved eukaryotic helicase that in the yeast $S$. cerevisiae is involved in at least two independent processes, integrity of mitochondrial DNA [8;11], and telomere length control [16]. We report that wild type cells exposed to zinc develop a transcriptional response that includes increased expression of several genes also induced by iron shortage. Gene activation did not affect to the entire Aft1-mediated regulon, but a specific subset that is highly enriched in siderophore transporterencoding genes. This transcription profile is reminiscent of the one observed by Crisp and coworkers [28;29], who demonstrated that disruption of heme biosynthesis in ironstarved cells blocks the activation of genes encoding the components of the reductive, high-affinity iron transport system, but not that of siderophore-utilization encoding genes. This observation would explain the transcription profile reported here, as it has been previously proposed that an excess of zinc interferes with the biosynthesis of heme, as it competes with iron for binding to ferrochelatase [30]. Our finding that in a pif1 mutant the induction of members of the Aft1 regulon by exposure to zinc is markedly attenuated could be explained by the higher iron content of this strain, which could also explain why further addition of iron to the medium improves only marginally tolerance to zinc compared with the wild type strain (Figure 4B).

We reported in the past [6] and confirm here (Figures 5 and 6) that exposure to zinc triggers a oxidative stress response that can be assessed by examination of the transcriptomic profile and the generation of ROS. In yeast both zinc deficiency [7] and zinc overload provokes oxidative stress. It is remarkable that a similar situation has been reported for neurons [31], which suggest that yeast could be a suitable model for mitochondrial zinc homeostasis studies. In this work we also observe that deletion of PIF1 decreases the generation of ROS induced by zinc (Figure 6) and results in a enhanced transcriptional response of genes encoding proteins relevant for protection against oxidative stress (i.e. GPX2, CTT1, TRX2, SOD1,..). While the total amount of glutathione is lower in the pif1 mutant, the fraction of reduced glutathione is clearly higher. This difference can be observed under normal growth conditions and it is exacerbated under zinc stress. We suggest that increased zinc tolerance of the pif1 mutant could be attributed at least in part, to a higher capacity to deal with the oxidative stress provoked by exposure to zinc. It can be hypothesized that sequestration of zinc in the mitochondria would protect from stress. This would fit with our observation that tolerance in the pif1 mutant seems to be quite specific for zinc stress, since this strain is not tolerant to other oxidative agents, but moderately sensitive instead.

Our data demonstrates that the absence of Pif1 protein in the mitochondria appears associated to two, apparently independent phenotypes: the loss of aconitase activity and the hypertolerance to zinc. What could be the explanation for the absence of aconitase activity associated to the lack of Pif1 protein in the mitochondria? It has been previously shown [17] that Aco1 binds to the nucleoid structure formed by yeast mtDNA, in order to compensate for the lack of other mtDNA proteins [32;33]. It must be noted the recent report that Aco1 is epistatic to Pif1 for mtDNA maintenance, due to its ability to bind to mtDNA through regions of the protein completely independent of those responsible for its catalytic activity [18]. We therefore hypothesize that, in the absence of Pif1, Aco1, would shift from an enzymatic role in TCA cycle to an mtDNA binding function. This would be consistent with the incapacity of the pif1 mutant to grow on respiratory carbon sources [13;34] and would explain, by a feed-back mechanism, the increased expression of $A C O 1$ observed in pif1 cells. It is suggestive that IDH1, which also associates to the mitochondrial nucleoid [35], is induced in the absence of PIF1 as well (Table 2). Further support to our hypothesis comes from our observation that cells expressing the K264A version of Pif1, which lacks helicase activity but still retains the capacity to bind DNA [15], display a phenotype of zinc sensitivity indistinguishable from that of the wild type strain (Figure 1A) and contain aconitase activity (Figure 8A). Expression of mitochondrially-targeted Pif1 significantly decreases the tolerance to the 
metal caused by the gene deletion. In contrast, expression in the pif1 $\Delta$ background of a nuclear-targeted version of Pif1 results in a phenotype equivalent to that of the gene deletion (i.e. increased zinc tolerance) and absence of aconitase activity. It is worth noting that cells expressing Pif1-m2, which display significant, but lower-than-normal levels of aconitase activity, do not completely mimic the sensitivity to zinc of wild type cells (Figure 1A). Failure to achieve a full wild type phenotype could be due to a leakage of this protein to nucleus, as proposed by Schulz and Zakian [16]. All these evidences demonstrate a relationship between the absence of Pif1 in the mitochondria, the levels of aconitase activity, and the tolerance to zinc in yeast cells.

It is more difficult to explain why the mitochondrial lack of Pif1 leads to zinc increased tolerance. One possibility would be that this effect is derived from the absence of aconitase activity (as suggested by Figure 8D). The aconitase system is generally accepted as a major marker of [Fe-S] cluster status in the cell [36] and, in turn, proper formation of Fe-S clusters represents an important signal for iron homeostatic mechanisms. It is suggestive that our transcriptomic profiling of pif1 $\Delta$ cells, reveals a 2 to 3 -fold increase in the expression of ACO1 and ACO2 genes, as well as of LEU1 and LYS4. LEU1 and LYS4 encode aconitase-like proteins which, similarly to Aco1, are Fe-S proteins of the [4Fe-4S] type [37;38]. Blocking of Fe-S biogenesis results in increased intracellular or mitochondrial iron content, as it is the case of mutation of NFS1 [39], frataxin (YTH1) [40] or GRX5 [41]. In addition, a recent report [42] has highlighted the fact that loss of mtDNA interferes with iron-sulfur cluster biogenesis. We suggest that the mtDNA-related function assumed by Aco1 (and perhaps Idh1) in the absence of Pif1 could lead to a misbalance of iron homeostasis, causing an accumulation of iron in the mitochondria which, subsequently, would explain the capacity of pif1 cells to cope with Zn overload. Alternatively, sequestration of zinc in the mitochondria by still unknown mechanisms might be the basis for zinc tolerance of the pif1 mutant. The accumulation of iron might be a consequence of increased $\mathrm{Fe}$ uptake (although we do not observe induction of genes encoding reductive iron transporters), triggered by a possible dissociation of Fe-S clusters from Aco1 or other ISC-containing proteins. It should be noted that we do not observe induction of FET3, which has been reported as a marker of impaired Fe-S clusters biosynthesis [19], indicating that this process is not altered in pif1 mutants. Dissociation of ISC may release sulfur, which may explain the inhibition of genes related with $S$ utilization identified in our microarray experiments.

In essence, our experiments define a scenario in which the moonlighting nature of yeast aconitase would be at the crossroad of the pleiotropic effect of pif1 deletion. Alteration in mitochondrial aconitase function would trigger a domino effect on iron homeostasis that might result in the altered zinc tolerance originally identified in the pif1 mutant [6], thus constituting a remarkable example of the intimate connection existing between the homeostatic mechanisms of different metals [43]. Further work is on the way to molecularly define the relationships between cellular aconitase functions and metal (zinc and iron) metabolism regulation. 


\section{ACKNOWLEDGEMENTS}

We thank V.A. Zakian for yeast strains; M. Geli, A. Dancis and D. Pain for antibodies; and D. Winge and D. Eide for fruitful discussions and advice. The excellent technical assistance of $\mathrm{A}$. Vilalta and M. Robledo is acknowledged. Thanks are given to the 'Serveis Científico-Tècnics' of the University of Barcelona for metal measurements.

\section{FUNDING}

Work was supported by grants GEN2006-27748-C2-1-E/SYS (SysMO), EUI200904147 (SysMo2) and BFU2008-04188-C03-01 to J.A.; BFU2007-60342 and BFU200911593 to A.C; and BIO2009-12513-C02-01 to S.A. (MICINN, Spain). J.A. and S.A. are recipients of "Ajut de Suport a les Activitats dels Grups de Recerca" (Grants 2009SGR1091 and 2009SGR-1457, respectively, Generalitat de Catalunya). M.G. is recipient of a MAE-AECID fellowship.

\section{FIGURE LEGENDS}

Figure 1. Lack of Pif1 confers tolerance to zinc. (A) Wild type strains BY4741 and YPH499 and their pif1 derivatives were spotted on YPD plates in the absence or presence of 5 or $7 \mathrm{mM} \mathrm{ZnCl}$, respectively. A strain carrying a pif1 allele devoid of helicase activity (pif1-K264A) is included. Plates were incubated for three (BY4741 background) or four (YPH499 background) days. (B) YPH499-derived strains carrying a deletion of PIF1 (pif1 $\Delta$ ) or expressing version of the protein targeted to the nucleus (pif1-m1) or to the mitochondria (pif1-m2) were spotted on YPD plates in the absence or presence of $5 \mathrm{mM} \mathrm{ZnCl}_{2}$ and grown for 4 days.

Figure 2. Effect of the pif1 mutation on total and mitochondrial zinc content.

Wild type BY4741 and its pif1 $\Delta$ derivative were grown as described under Experimental Procedures. Cells were collected from untreated (-) or $5 \mathrm{mM} \mathrm{ZnCl}_{2}$-treated cultures (+) at the moment of zinc addition $(0 \mathrm{~h})$ or after $24 \mathrm{~h}$. Total zinc (upper panel) or mitochondrial zinc (lower panel) contents were measured. Data are mean \pm SD from 6 independent experiments.

Figure 3. Effect of the pif1 mutation on total and mitochondrial iron content. Cells were cultured as in legend of Figure 2 and total iron (upper panel) or mitochondrial iron (lower panel) contents were measured. Data are mean \pm SD from 6 independent experiments. The Newman-Keuls Multiple Comparison Test was used $\left({ }^{*}\right.$, $p<0.05 ;{ }^{* *}, p<0.01$ )

Figure 4. Effect of iron availability on zinc tolerance of wild type and pif1 cells. (A). Wild type strain BY4741 and the indicated kanMX deletion derivatives were spotted on YPD plates with or without $5 \mathrm{mM} \mathrm{ZnCl}_{2}$. Growth was monitored after four days. (B). Wild type strain BY4741 (closed bars) and the pif1 derivative (open bars) were inoculated at $\mathrm{OD}_{600} 0.01$ on liquid YPD medium containing $4 \mathrm{mM} \mathrm{ZnCl}$, with no further addition (N/A), $75 \mu \mathrm{M}$ BPS or $100 \mu \mathrm{M} \mathrm{Fe}\left(\mathrm{NH}_{4}\right)_{2}\left(\mathrm{SO}_{4}\right)_{2}$. Growth was monitored at $595 \mathrm{~nm}$ after $48 \mathrm{~h}$. For each strain, data correspond to growth relative to that of the culture without added zinc and is presented as the mean \pm SEM from three cultures.

Figure 5. Gene expression changes induced by lack of PIF1 in the absence or the presence of excess of zinc. Cluster analysis of the expression profiles acquired. The selected datasets (pif1 mutant compared with wild type cells growing on YPD or YPD plus $5 \mathrm{mM}$ zinc for $60 \mathrm{~min}$, and wild type or pif1 cells in the absence of added zinc 
compared with those growing for $60 \mathrm{~min}$ in YPD plus $5 \mathrm{mM}$ zinc) were hierarchically clustered (complete linkage clustering, uncentered correlation) by means of the Cluster (v3.0) software and visualized with TreeView (v1.60) (Eisen et al., 1998). Numbers refers to selected cluster that are described in the main text. Color codes for gene function are as follows: red, glycogen metabolism; yellow, oxidative stress response; green, iron homeostasis.

Figure 6. Effect of pif1 $\Delta$ mutation in zinc-induced ROS formation. (A) Wild type and pif1 $\Delta$ cultures were pre-incubated with dihydrorhodamine 123 as indicated and then exposed to $10 \mathrm{mM} \mathrm{ZnCl}_{2}$ or $5 \mathrm{mM} \mathrm{H}_{2} \mathrm{O}_{2}$ for 60 and 90 min (the latter not shown). Micrographs of representative fields are shown. Brightness of $\mathrm{H}_{2} \mathrm{O}_{2}$-treated cells has been attenuated with respect of the rest of micrographs to allow proper visualization.

(B) The intensity of fluorescence from around 600 cells (around 20 fields) was integrated as described under Experimental Procedures after the indicated periods of treatment. Data are expressed as mean \pm SEM. (C) Three dilutions of the BY4741 wild type strain and its pif1 $\Delta$ derivative were spotted on YPD plates containing $\mathrm{ZnCl}_{2}(5$ $\mathrm{mM})$, hydrogen peroxide $(4 \mathrm{mM})$, diamide $(2.5 \mathrm{mM})$ or menadione $(0.125 \mathrm{mM})$ and incubated for 2 days (4 days for the plate containing $\mathrm{ZnCl}_{2}$ ) until growth was recorded.

Figure 7. Glutathione content in wild type and pif1 cells. BY4741 strain (open bars) and its pif1 $\Delta$ derivative (closed bars) were grown for $42 \mathrm{~h}$ in the absence or the presence of the indicated concentrations of $\mathrm{ZnCl}_{2}$. Total and oxidized (GSSG) glutathione levels were determined and referred to $\mathrm{mg}$ of total protein. The reduced / oxidized glutathione ratio is also represented (lower panel). Data are mean \pm SEM from 3-4 independent experiments.

Figure 8. Functional link between Pif1, Aco1 and zinc tolerance. (A) Wild type YPH499 cells and its isogenic derivatives pif1 $\Delta$, pif1K264A (pif1*), pif1-m1 and pif1-m2 were grown to stationary phase and aconitase activity was measured. Aconitase activity in a strain lacking $A C O 1$ is included for comparison. (B) Wild type BY4741 and pif1 $\Delta$ cells were grown for $24 \mathrm{~h}$ in the absence (open bars) or the presence (closed bars) of $5 \mathrm{mM} \mathrm{ZnCl}_{2}$ and aconitase activity was measured. (C) Cells were grown as in (B) and samples were processed to quantify total (closed bars), mitochondrial (open bars) and non-mitochondrial (stripped bars) aconitase protein using an ELISA method (see Experimental Procedures). In all cases, data are mean \pm SD from four independent experiments. (D) Dilutions of the indicated strains (BY4741 background) were spotted on YPD plates in the presence or the absence of $7 \mathrm{mM} \mathrm{ZnCl}$. Growth was monitored after 3 days. 


\section{Reference List}

1 Eide,D.J. (2009) Homeostatic and adaptive responses to zinc deficiency in Saccharomyces cerevisiae. J. Biol. Chem., 284, 18565-18569.

2 Macdiarmid,C.W., Milanick,M.A. and Eide,D.J. (2002) Biochemical properties of vacuolar zinc transport systems of Saccharomyces cerevisiae. J. Biol. Chem., 277, 39187-39194.

3 Macdiarmid,C.W., Gaither,L.A. and Eide,D. (2000) Zinc transporters that regulate vacuolar zinc storage in Saccharomyces cerevisiae. EMBO J., 19, 2845-2855.

4 Ramsay,L.M. and Gadd,G.M. (1997) Mutants of Saccharomyces cerevisiae defective in vacuolar function confirm a role for the vacuole in toxic metal ion detoxification. FEMS Microbiol. Lett., 152, 293-298.

5 Regalla,L.M. and Lyons,T. (2006) Zinc in yeast: mechanisms involved in homeostasis. In Molecular Biology of Metal Homeostasis and Detoxification: From Microbes to Man (Tamás,M. and Martinoia,E. Eds.), pp. 37-58. Springer-Verlag, Berlin.

6 Pagani,M.A., Casamayor,A., Serrano,R., Atrian,S. and Arino,J. (2007) Disruption of iron homeostasis in Saccharomyces cerevisiae by high zinc levels: a genome-wide study. Mol. Microbiol., 65, 521-537.

7 Wu,C.Y., Bird,A.J., Winge,D.R. and Eide,D.J. (2007) Regulation of the yeast TSA1 peroxiredoxin by ZAP1 is an adaptive response to the oxidative stress of zinc deficiency. J. Biol. Chem., 282, 2184-2195.

8 Foury,F. and Kolodynski,J. (1983) pif mutation blocks recombination between mitochondrial rho+ and rho- genomes having tandemly arrayed repeat units in Saccharomyces cerevisiae. Proc. Natl. Acad. Sci. U. S. A, 80, 5345-5349.

9 Bochman,M.L., Sabouri,N. and Zakian,V.A. (2010) Unwinding the functions of the Pif1 family helicases. DNA Repair (Amst), 9, 237-249.

10 Cheng,X., Dunaway,S. and Ivessa,A.S. (2007) The role of Pif1p, a DNA helicase in Saccharomyces cerevisiae, in maintaining mitochondrial DNA. Mitochondrion., 7, 211222.

11 Lahaye,A., Stahl,H., Thines-Sempoux,D. and Foury,F. (1991) PIF1: a DNA helicase in yeast mitochondria. EMBO J., 10, 997-1007.

12 Lahaye,A., Leterme,S. and Foury,F. (1993) PIF1 DNA helicase from Saccharomyces cerevisiae. Biochemical characterization of the enzyme. J. Biol. Chem., 268, 26155-26161.

13 Van Dyck,E., Foury,F., Stillman,B. and Brill,S.J. (1992) A single-stranded DNA binding protein required for mitochondrial DNA replication in $S$. cerevisiae is homologous to $E$. coli SSB. EMBO J., 11, 3421-3430.

14 Zhou,J., Monson,E.K., Teng,S.C., Schulz,V.P. and Zakian,V.A. (2000) Pif1p helicase, a catalytic inhibitor of telomerase in yeast. Science, 289, 771-774. 
15 Boule,J.B., Vega,L.R. and Zakian,V.A. (2005) The yeast Pif1p helicase removes telomerase from telomeric DNA. Nature, 438, 57-61.

16 Schulz,V.P. and Zakian,V.A. (1994) The Saccharomyces PIF1 DNA helicase inhibits telomere elongation and de novo telomere formation. Cell, 76, 145-155.

17 Chen,X.J., Wang,X., Kaufman,B.A. and Butow,R.A. (2005) Aconitase couples metabolic regulation to mitochondrial DNA maintenance. Science, 307, 714-717.

18 Chen,X.J., Wang,X. and Butow,R.A. (2007) Yeast aconitase binds and provides metabolically coupled protection to mitochondrial DNA. Proc. Natl. Acad. Sci. U. S. A, 104, 13738-13743.

19 Chen,O.S., Crisp,R.J., Valachovic,M., Bard,M., Winge,D.R. and Kaplan,J. (2004) Transcription of the yeast iron regulon does not respond directly to iron but rather to iron-sulfur cluster biosynthesis. J. Biol. Chem., 279, 29513-29518.

20 Jeffery,C.J. (2009) Moonlighting proteins--an update. Mol. Biosyst., 5, 345-350.

21 Gancedo,C. and Flores,C.L. (2008) Moonlighting proteins in yeasts. Microbiol. Mol. Biol. Rev., 72, 197-210.

22 Alberola,T.M., Garcia-Martinez,J., Antunez,O., Viladevall,L., Barcelo,A., Arino,J. and Perez-Ortin,J.E. (2004) A new set of DNA macrochips for the yeast Saccharomyces cerevisiae: features and uses. Int Microbiol., 7, 199-206.

23 Viladevall,L., Serrano,R., Ruiz,A., Domenech,G., Giraldo,J., Barcelo,A. and Arino,J. (2004) Characterization of the calcium-mediated response to alkaline stress in Saccharomyces cerevisiae. J. Biol. Chem., 279, 43614-43624.

24 Herrero,J., Al Shahrour,F., Diaz-Uriarte,R., Mateos,A., Vaquerizas,J.M., Santoyo,J. and Dopazo,J. (2003) GEPAS: A web-based resource for microarray gene expression data analysis. Nucleic Acids Res., 31, 3461-3467.

25 Brazma,A. and Vilo,J. (2000) Gene expression data analysis. FEBS Lett., 480, 1724.

26 Hong,E.L., Balakrishnan,R., Dong,Q., Christie,K.R., Park,J., Binkley,G., Costanzo,M.C., Dwight,S.S., Engel,S.R., Fisk,D.G., Hirschman,J.E., Hitz,B.C., Krieger,C.J., Livstone,M.S., Miyasato,S.R., Nash,R.S., Oughtred,R., Skrzypek,M.S., Weng,S., Wong,E.D., Zhu,K.K., Dolinski,K., Botstein,D. and Cherry,J.M. (2008) Gene Ontology annotations at SGD: new data sources and annotation methods. Nucleic Acids Res., 36, D577-D581.

27 Lyons, T.J., Villa,N.Y., Regalla,L.M., Kupchak,B.R., Vagstad,A. and Eide,D.J. (2004) Metalloregulation of yeast membrane steroid receptor homologs. Proc. Natl. Acad. Sci. U. S. A, 101, 5506-5511.

28 Crisp,R.J., Adkins,E.M., Kimmel,E. and Kaplan,J. (2006) Recruitment of Tup1p and Cti6p regulates heme-deficient expression of Aft1p target genes. EMBO J., 25, 512521.

29 Crisp,R.J., Pollington,A., Galea,C., Jaron,S., Yamaguchi-Iwai,Y. and Kaplan,J. (2003) Inhibition of heme biosynthesis prevents transcription of iron uptake genes in yeast. J. Biol. Chem., 278, 45499-45506. 
30 Camadro,J.M. and Labbe,P. (1988) Purification and properties of ferrochelatase from the yeast Saccharomyces cerevisiae. Evidence for a precursor form of the protein. J. Biol. Chem., 263, 11675-11682.

31 Hao,Q. and Maret,W. (2005) Imbalance between pro-oxidant and pro-antioxidant functions of zinc in disease. J. Alzheimers. Dis., 8, 161-170.

32 Kucej,M. and Butow,R.A. (2007) Evolutionary tinkering with mitochondrial nucleoids. Trends Cell Biol., 17, 586-592.

33 Shadel,G.S. (2005) Mitochondrial DNA, aconitase 'wraps' it up. Trends Biochem. Sci., 30, 294-296.

34 O'Rourke,T.W., Doudican,N.A., Mackereth,M.D., Doetsch,P.W. and Shadel,G.S. (2002) Mitochondrial dysfunction due to oxidative mitochondrial DNA damage is reduced through cooperative actions of diverse proteins. Mol. Cell Biol., 22, 40864093.

35 Chen,X.J. and Butow,R.A. (2005) The organization and inheritance of the mitochondrial genome. Nat. Rev. Genet., 6, 815-825.

36 Pierik,A.J., Netz,D.J. and Lill,R. (2009) Analysis of iron-sulfur protein maturation in eukaryotes. Nat. Protoc., 4, 753-766.

37 Lill,R., Dutkiewicz,R., Elsasser,H.P., Hausmann,A., Netz,D.J., Pierik,A.J., Stehling,O., Urzica,E. and Muhlenhoff,U. (2006) Mechanisms of iron-sulfur protein maturation in mitochondria, cytosol and nucleus of eukaryotes. Biochim. Biophys. Acta, 1763, 652-667.

38 Lill,R. and Muhlenhoff,U. (2008) Maturation of iron-sulfur proteins in eukaryotes: mechanisms, connected processes, and diseases. Annu. Rev. Biochem., 77, 669-700.

39 Li,J., Kogan,M., Knight,S.A., Pain,D. and Dancis,A. (1999) Yeast mitochondrial protein, $\mathrm{Nfs} 1 \mathrm{p}$, coordinately regulates iron-sulfur cluster proteins, cellular iron uptake, and iron distribution. J. Biol. Chem., 274, 33025-33034.

40 Santos,R., Dancis,A., Eide,D., Camadro,J.M. and Lesuisse,E. (2003) Zinc suppresses the iron-accumulation phenotype of Saccharomyces cerevisiae lacking the yeast frataxin homologue (Yfh1). Biochem. J., 375, 247-254.

41 Rodriguez-Manzaneque,M.T., Tamarit,J., Belli,G., Ros,J. and Herrero,E. (2002) Grx5 is a mitochondrial glutaredoxin required for the activity of iron/sulfur enzymes. Mol. Biol. Cell, 13, 1109-1121.

42 Veatch,J.R., McMurray,M.A., Nelson,Z.W. and Gottschling,D.E. (2009) Mitochondrial dysfunction leads to nuclear genome instability via an iron-sulfur cluster defect. Cell, 137, 1247-1258.

43 Atkinson,A. and Winge,D.R. (2009) Metal acquisition and availability in the mitochondria. Chem. Rev., 109, 4708-4721.

44 Sikorski,R.S. and Hieter,P. (1989) A system of shuttle vectors and yeast host strains designed for efficient manipulation of DNA in Saccharomyces cerevisiae. Genetics, 122, 19-27. 
Table 1 Strains used in this work

\begin{tabular}{|c|c|c|}
\hline Strain & Genotype & Source/Reference \\
\hline BY4741 & MATa his $3 \Delta 1$ leu2 $\Delta 0$ met15 $\Delta 0$ ura3 $\Delta 0$ & Euroscarf \\
\hline BY4741 pif1 & BY4741 pif1::kanMX & Euroscarf \\
\hline BY4741 aco1 & BY4741 aco1::kanMX & Euroscarf \\
\hline BY4741 fet3 & BY4741 fet3::kanMX & Euroscarf \\
\hline BY4741 fit3 & BY4741 fit3::kanMX & Euroscarf \\
\hline BY4741 ftr1 & BY4741 ftr1::kanMX & Euroscarf \\
\hline W303-1A & MATa ade 2 can 1 his 3 leu 2 trp1 ura3 & R. Rothstein \\
\hline LBY65 & W303-1A pif1::kanMX & This work \\
\hline DBY746 & MAT $\alpha$ his3-1 leu2-3,112 ura3-52 trp1-289 & D. Botstein \\
\hline LBY67 & DBY746 pif1::kanMX & This work \\
\hline YPH499 & $\begin{array}{l}\text { Mata ura3-52 lys2-801 ade2-101 trp1- } 463 \text { his3- } \\
\Delta 200 \text { leu2- } \Delta 1\end{array}$ & [44] \\
\hline YPH499 pif1 & YPH499 pif1::TRP1 & [16] \\
\hline pif1-K264A & YPH499 pif1-K264A & [14] \\
\hline YPH499 pif1-m1 & YPH499 pif1-m1 & [14] \\
\hline YPH499 pif1-m2 & YPH499 pif1-m2 & [14] \\
\hline
\end{tabular}

Licenced copy. Copying is not permitted, except with prior permission and as allowed by law.

(C) 2010 The Authors Journal compilation (c) 2010 Portland Press Limited 
Table 2 Genes differentially induced (>1.8-fold) in a pif1 $\Delta$ mutant. The asterisk indicates gene products with recognized mitochondrial function

\begin{tabular}{|c|c|c|c|c|}
\hline ORF & Gene & $\begin{array}{l}\text { Induction } \\
\text { (-fold) }\end{array}$ & Mit. & Features \\
\hline \multicolumn{5}{|c|}{ TCA and aconitase-like. } \\
\hline $\begin{array}{l}\text { YOR135C } \\
\text { YLR304C } \\
\text { YGL009C } \\
\text { YOR136W }\end{array}$ & $\begin{array}{l}\text { IRC14 } \\
\text { ACO1 } \\
\text { LEU1 } \\
\text { IDH2 }\end{array}$ & $\begin{array}{l}3.45 \\
3.13 \\
2.96 \\
2.67\end{array}$ & $\begin{array}{l}\left({ }^{*}\right) \\
\left({ }^{*}\right)\end{array}$ & $\begin{array}{l}\text { Partially overlaps IDH1. } \\
\text { Aconitase, required for the TCA cycle and for mitochondrial genome maintenance. } \\
\text { Isopropylmalate isomerase (Leu biosynthesis pathway) } \\
\text { Subunit of mitochondrial } \mathrm{NAD}(+) \text {-dependent isocitrate dehydrogenase }\end{array}$ \\
\hline YDR234W & LYS4 & 2.50 & $\left({ }^{*}\right)$ & $\begin{array}{l}\text { Homoaconitase, catalyzes the conversion of homocitrate to homoisocitrate (Lys } \\
\text { biosynthesis pathway) }\end{array}$ \\
\hline $\begin{array}{l}\text { YNL037C } \\
\text { YJL200C }\end{array}$ & $\begin{array}{l}\text { IDH1 } \\
\text { ACO2 }\end{array}$ & $\begin{array}{l}2.37 \\
1.84\end{array}$ & $\begin{array}{l}(*) \\
(*)\end{array}$ & $\begin{array}{l}\text { Subunit of mitochondrial } \mathrm{NAD}(+) \text {-dependent isocitrate dehydrogenase } \\
\text { Putative mitochondrial aconitase isozyme }\end{array}$ \\
\hline
\end{tabular}

Hypoxia/anaerobic/respiratory

$\begin{array}{lll}\text { YGL162W } & \text { SUT1 } & \mathbf{3 . 2 2} \\ \text { YIL011W } & \text { TIR3 } & \mathbf{2 . 6 3} \\ \text { YKR066C } & \text { CCP1 } & \mathbf{2 . 0 0} \\ \text { YKL109W } & \text { HAP4 } & \mathbf{1 . 9 1} \\ \text { YER011W } & \text { TIR1 } & \mathbf{1 . 8 5}\end{array}$

\section{Helicase activity}

$\begin{array}{lll}\text { YMR287C } & \text { DSS1 } & 2.57 \\ \text { YDL160C } & \text { DHH1 } & 2.32\end{array}$

YHR218W YHR218W 1.81

Other

\begin{tabular}{|c|c|c|}
\hline YKR093W & PTR2 & 3.22 \\
\hline YLL013C & PUF3 & 2.90 \\
\hline YDL037C & BSC1 & 2.79 \\
\hline YMR153W & NUP53 & 2.73 \\
\hline YMR068W & AVO2 & 2.72 \\
\hline YCL020W & YCLO20W & 2.67 \\
\hline YBR040W & FIG1 & 2.62 \\
\hline YMR211W & DML1 & 2.55 \\
\hline YNL202W & SPS19 & 2.41 \\
\hline YOL041C & NOP12 & 2.28 \\
\hline $\begin{array}{l}\text { YKL161C } \\
\text { YHR036W } \\
\text { YNL023C } \\
\text { YHR072W }\end{array}$ & $\begin{array}{l}\text { YKL161C } \\
\text { BRL1 } \\
\text { FAP1 } \\
\text { ERG7 }\end{array}$ & $\begin{array}{l}2.25 \\
2.18 \\
2.14 \\
2.09\end{array}$ \\
\hline YPL144W & POC4 & 2.08 \\
\hline YFL-TyA & YFL-TyA & 2.05 \\
\hline YGL194C & HOS2 & 2.03 \\
\hline YLR382C & NAM2 & 2.00 \\
\hline YDL231C & BRE4 & 1.95 \\
\hline YDR345C & HXT3 & 1.93 \\
\hline YBL103C & RTG3 & 1.90 \\
\hline YBR238C & YBR238C & 1.89 \\
\hline YOR178C & GAC1 & 1.83 \\
\hline YIL009W & FAA3 & 1.83 \\
\hline YDL021W & GPM2 & 1.83 \\
\hline YJL187C & SWE1 & 1.83 \\
\hline YOL105C & WSC3 & 1.83 \\
\hline YBR177C & EHT1 & 1.82 \\
\hline YAR042W & SWH1 & 1.81 \\
\hline YBR001C & NTH2 & 1.81 \\
\hline YNL197C & WHI3 & 1.80 \\
\hline \multicolumn{3}{|c|}{ Uncharacterized } \\
\hline YKL071W & YKL07IW & 2.86 \\
\hline YHL049C & YHLO49C & 2.52 \\
\hline YER076C & YER076C & 2.21 \\
\hline YBR113W & YBR113W & 2.20 \\
\hline YGL088W & YGLO88W & 2.07 \\
\hline YGL239C & YGL239C & 2.06 \\
\hline YBL012C & YBL012C & 1.88 \\
\hline YJL078C & PRY3 & 1.88 \\
\hline YFL032W & YFL032W & 1.86 \\
\hline
\end{tabular}

Transcription factor involved in induction of hypoxic gene expression Cell wall mannoprotein expressed under anaerobic conditions

${ }^{*}$ ) Mitochondrial cytochrome-c peroxidase; degrades reactive oxygen species in mitochondria Major subunit of the Hap2p/3p/4p/5p CCAAT-binding complex Cell wall mannoprotein induced by anaerobiosis

$\left(^{*}\right) \quad 3 '-5$ ' exoribonuclease, associated with the ATP-dependent RNA helicase Suv3p Cytoplasmic DExD/H-box helicase, stimulates mRNA decapping Helicase-like protein encoded within the telomeric $Y^{\prime}$ element

Integral membrane peptide transporter, mediates transport of di- and tri-peptides

$\left({ }^{*}\right)$ Protein of the mitochondrial outer surface

Protein of unconfirmed function

Subunit of the nuclear pore complex (NPC)

Component of a complex containing the Tor2p kinase and other proteins

Retrotransposon TYA Gag gene co-transcribed with TYB Pol

Integral membrane protein required for efficient mating

${ }^{*}$ ) Essential protein involved in mtDNA inheritance,

Peroxisomal 2,4-dienoyl-CoA reductase

Nucleolar protein involved in pre-25S rRNA processing and biogenesis of large 60S ribosomal subunit

Protein kinase implicated in the SIt2p signaling pathway

Essential nuclear envelope integral membrane protein

Protein that binds to Fpr1p, conferring rapamycin resistance

Lanosterol synthase, an essential enzyme in ergosterol biosynthesis

Component of a heterodimeric Poc4p-Irc25p chaperone involved in assembly of alpha subunits into the $20 \mathrm{~S}$ proteasome

Histone deacetylase

${ }^{*}$ Mitochondrial leucyl-tRNA synthetase

Zinc finger protein containing five transmembrane domains

Low affinity glucose transporter of the major facilitator superfamily

Basic helix-loop-helix-leucine zipper TF involved in the retrograde and TOR pathways

Mitochondrial membrane protein

Regulatory subunit for Glc7p type-1 protein phosphatase

Long chain fatty acyl-CoA synthetase

Homolog of Gpm1p phosphoglycerate mutase

Protein kinase that regulates the G2/M transition by inhibition of Cdc28p kinase activity

Partially redundant sensor-transducer of the stress-activated PKC1-MPK1 pathway

(*) Acyl-coenzymeA:ethanol O-acyltransferase

Protein similar to mammalian oxysterol-binding protein

${ }^{*}$ ) Putative neutral trehalase

RNA binding protein that sequesters CLN3 mRNA in cytoplasmic foci

Putative protein of unknown function

Putative protein of unknown function

$\left(^{*}\right)$ Putative protein of unknown function

Dubious open reading frame, partially overlaps the verified gene CYC8

Dubious open reading frame, partially overlaps snR10

Dubious open reading frame, partially overlaps verified gene CSE1

Dubious open reading frame

Protein of unknown function

Dubious open reading frame, partially overlaps the verified gene HAC1/YFL031W 
A

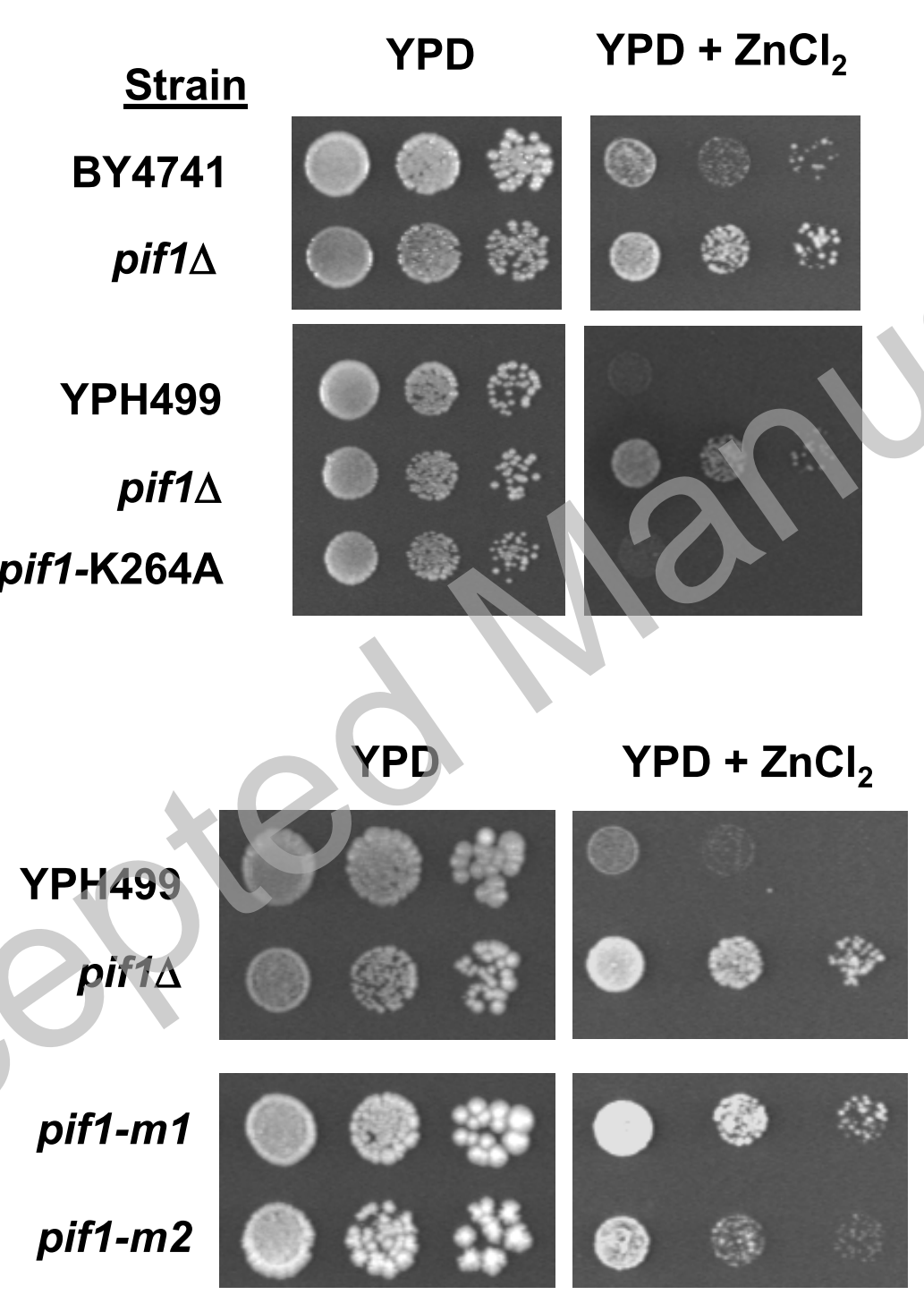

Figure 1. Guirola et al. 

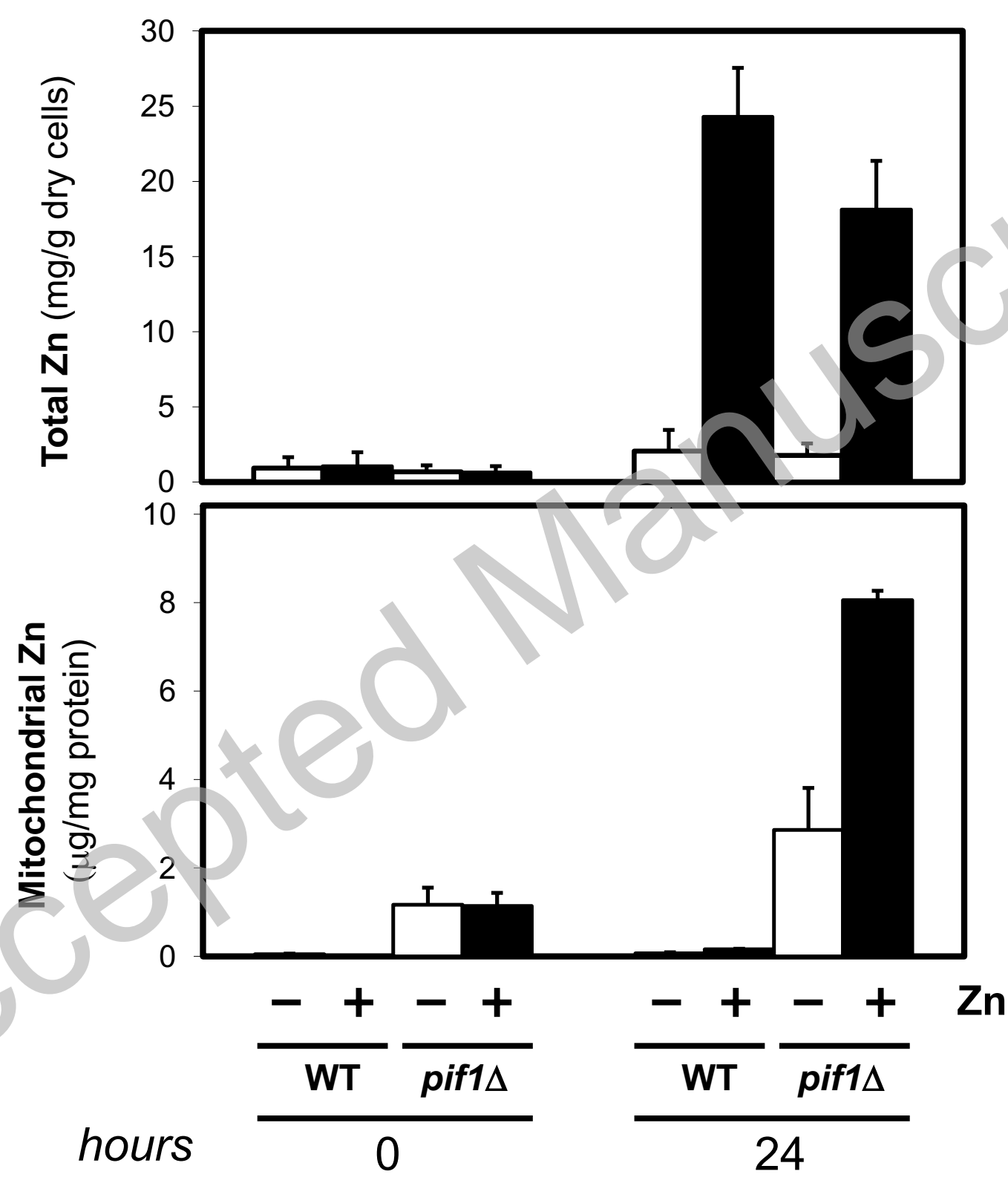

Figure 2. Guirola et al. 
B Biochemical Journal Immediate Publication. Published on 21 Sep 2010 as manuscript BJ20101032

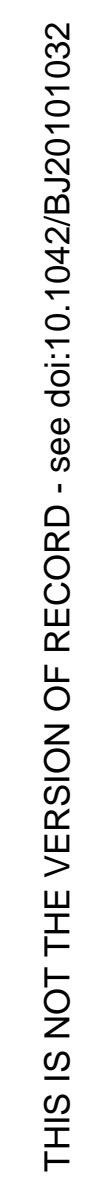

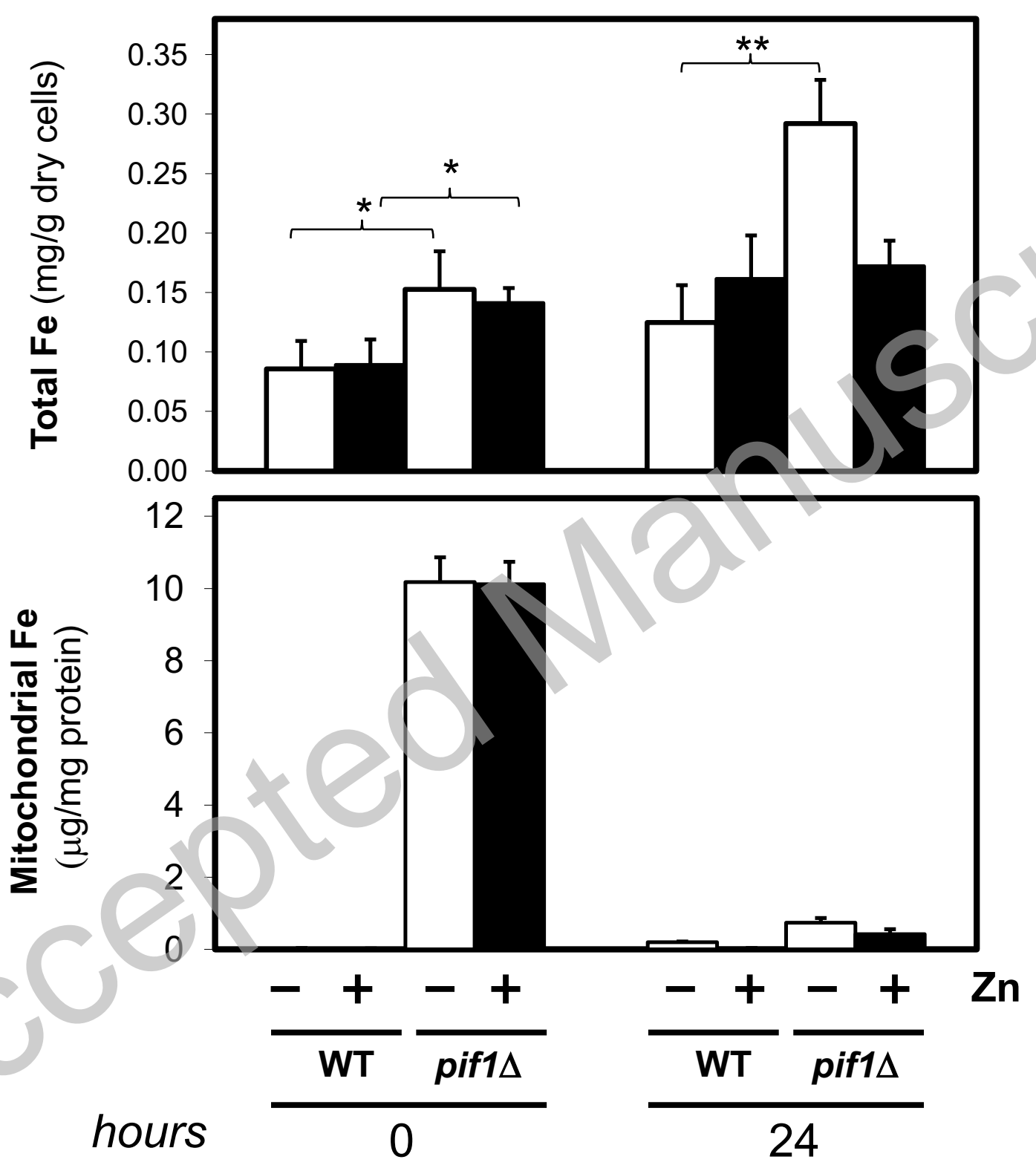

Figure 3. Guirola et al. 
A

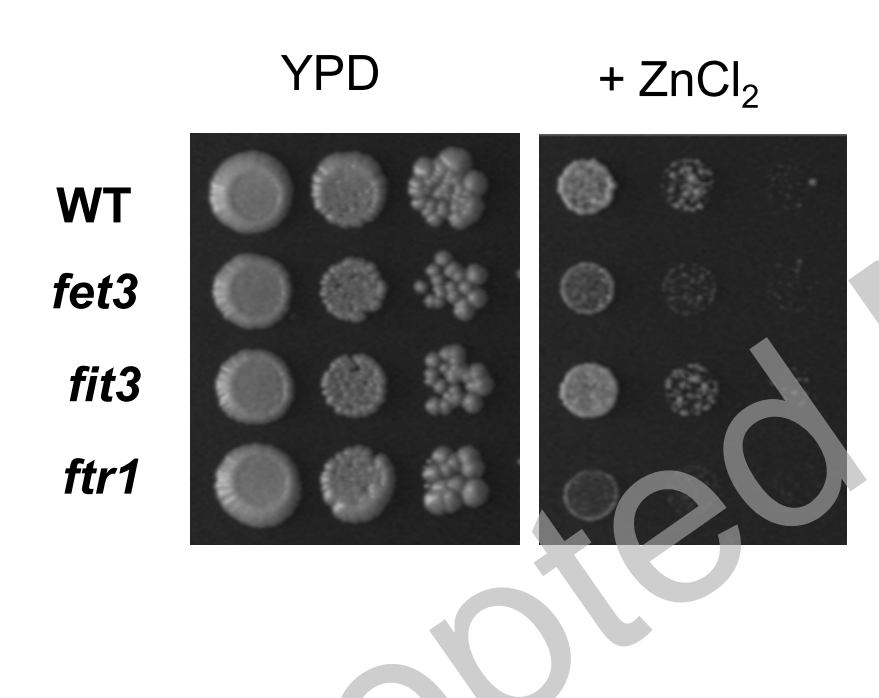

B

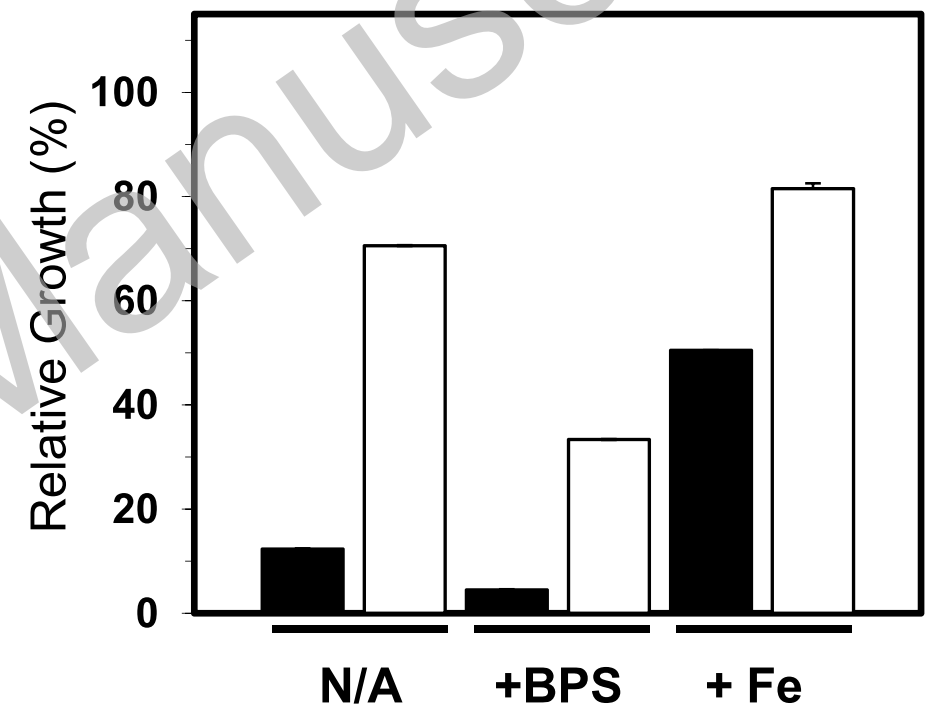

Figure 4. Guirola et al. 


\section{B Biochemical Journal Immediate Publication. Published on 21 Sep 2010 as manuscript BJ20101032}

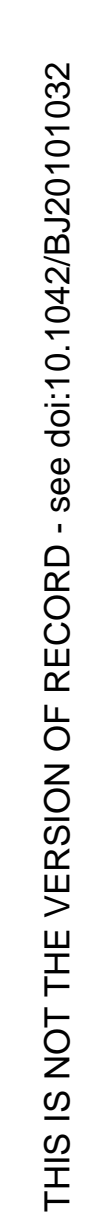

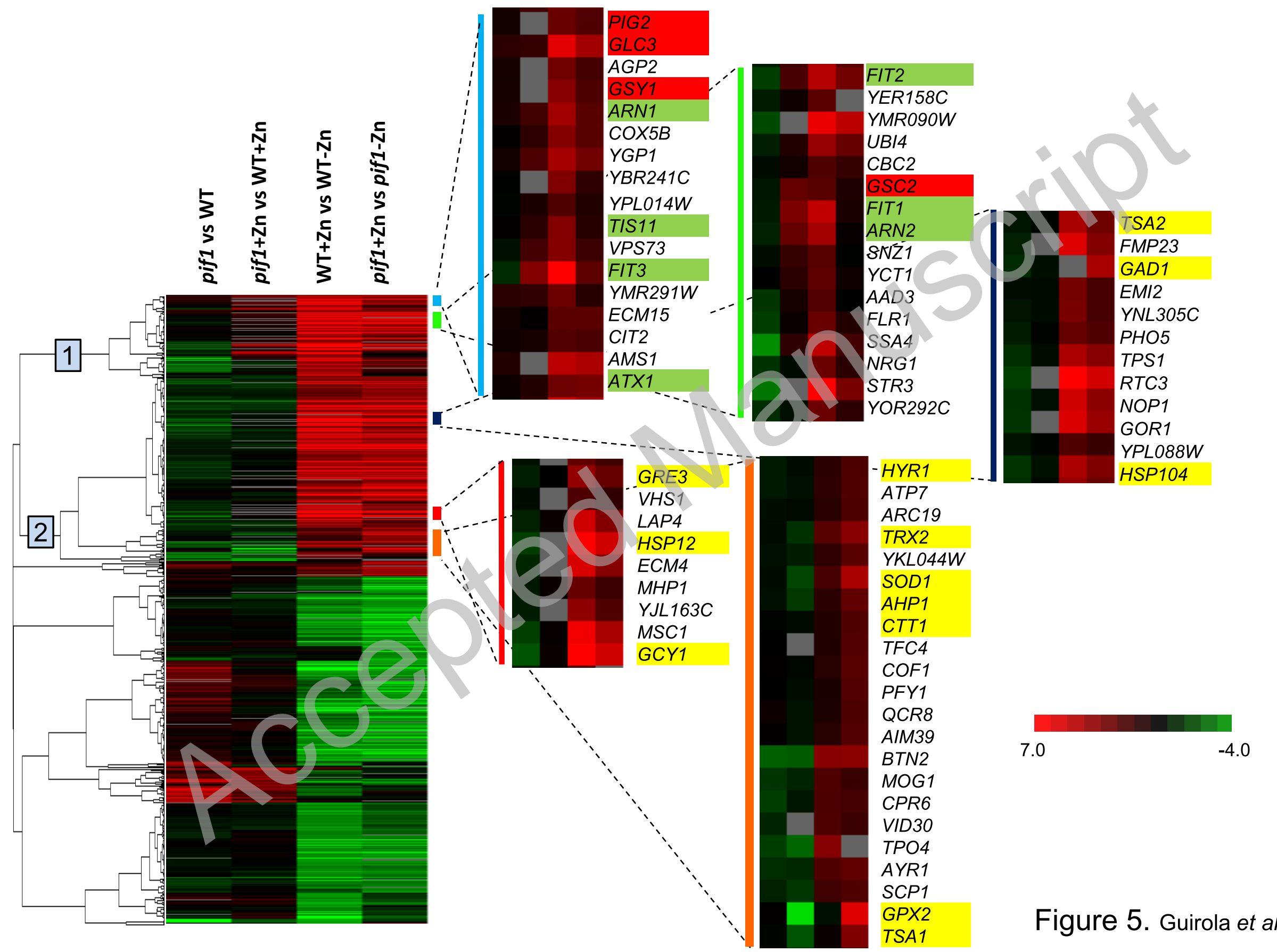

Licenced copy. Copying is not permitted, except with prior permission and as allowed by law. (C) 2010 The Authors Journal compilation (C) 2010 Portland Press Limited 
A)

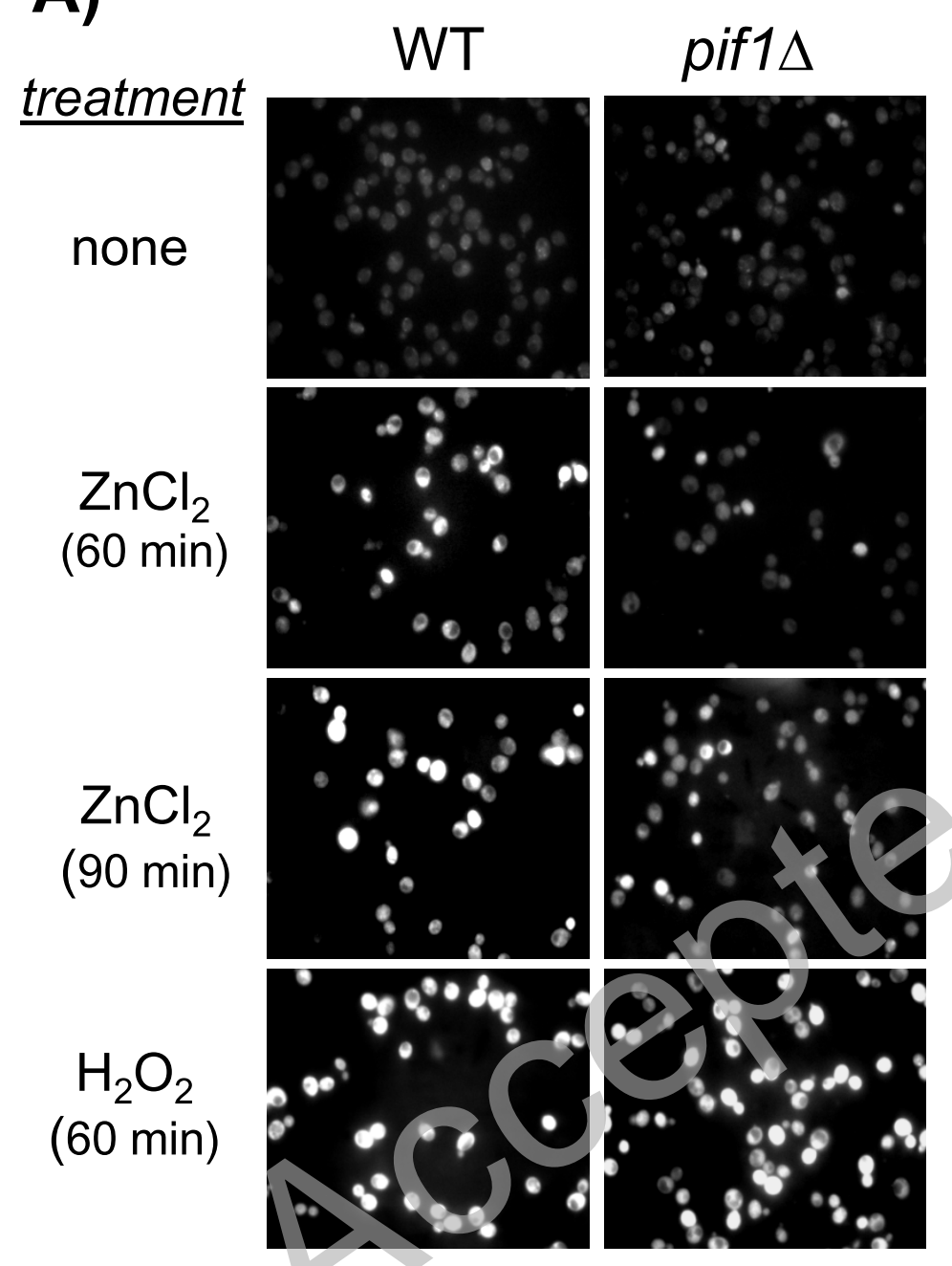

B)

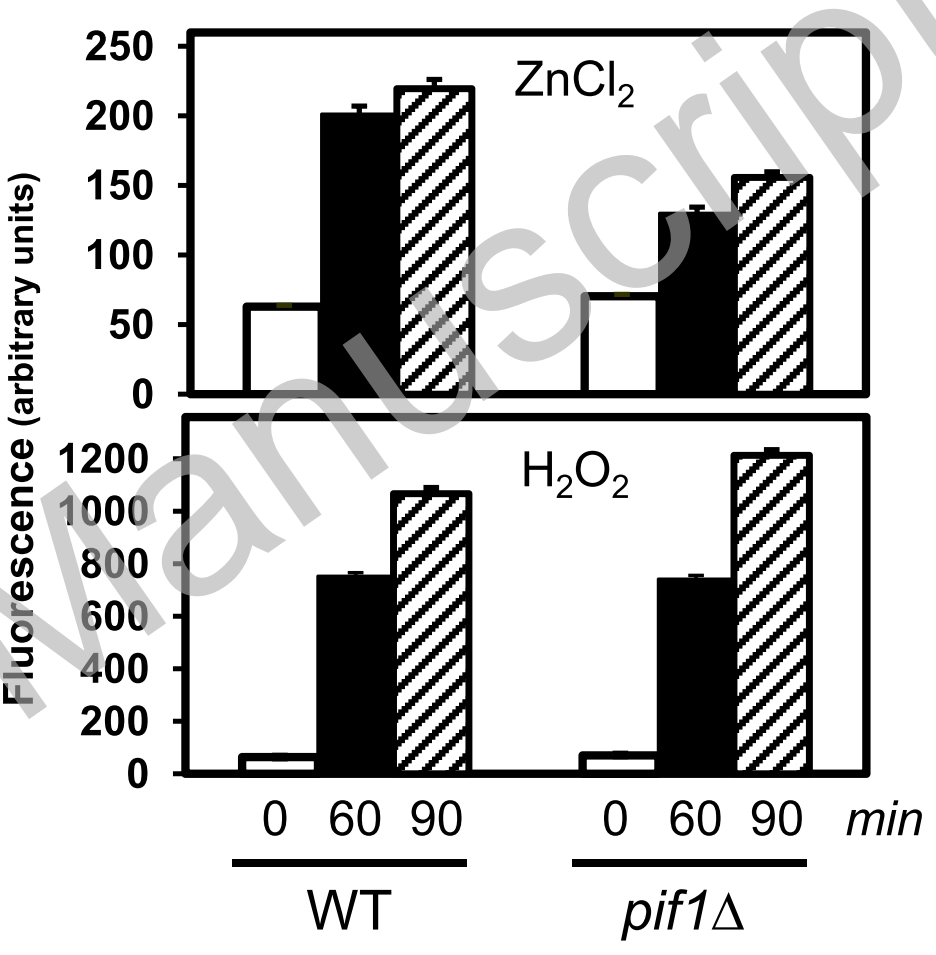

C)

\begin{tabular}{|c|c|c|c|c|}
\hline YPD & $\mathrm{ZnCl}_{2}$ & $\mathrm{H}_{2} \mathrm{O}_{2}$ & Diamide & Menadione \\
\hline & (9) 0 웅 & 0 & $\begin{array}{l}0 \\
0 \\
0\end{array}$ & 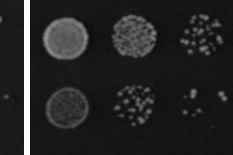 \\
\hline
\end{tabular}

Figure 6. Guirola et al. 


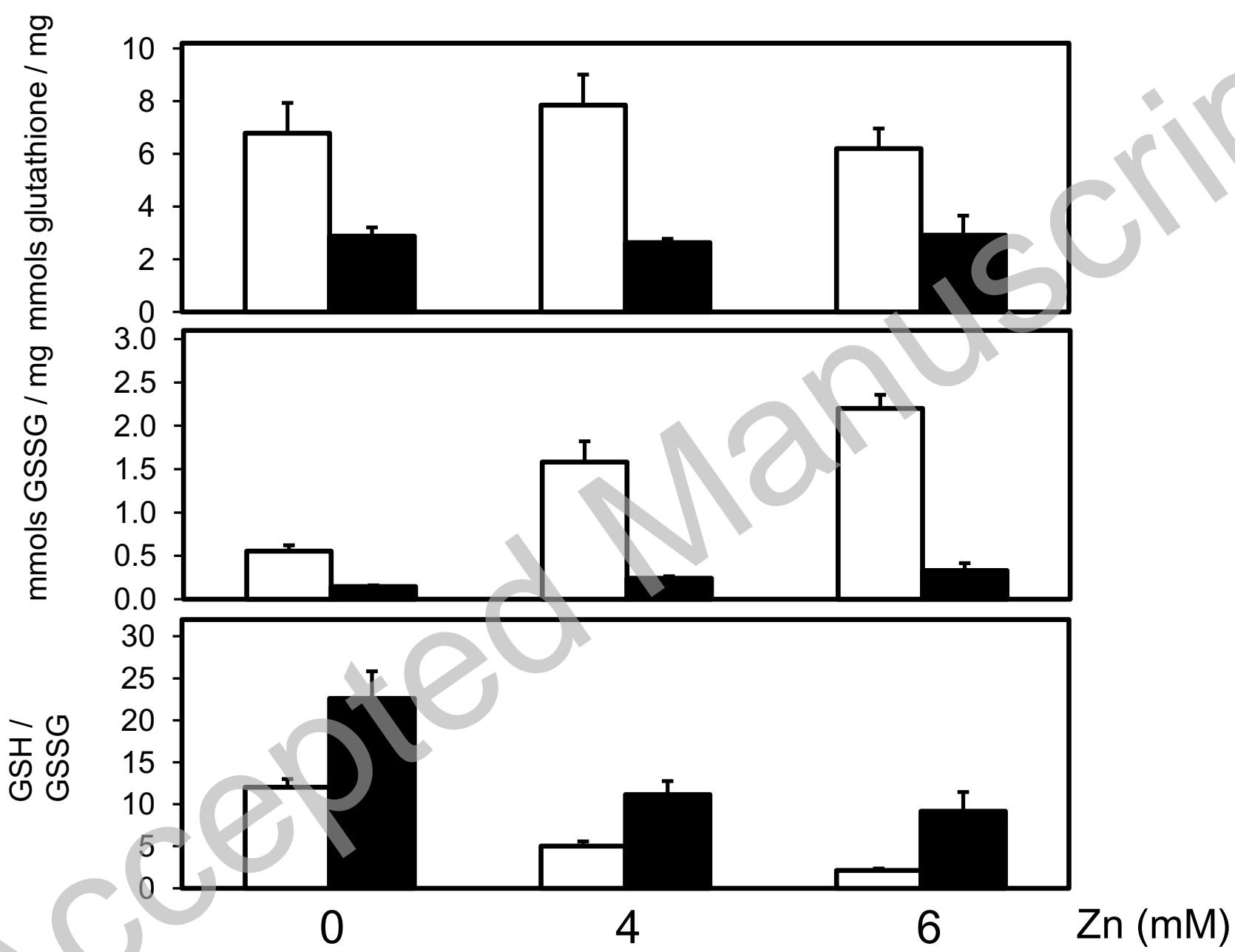

Figure 7. Guirola et al. 
A
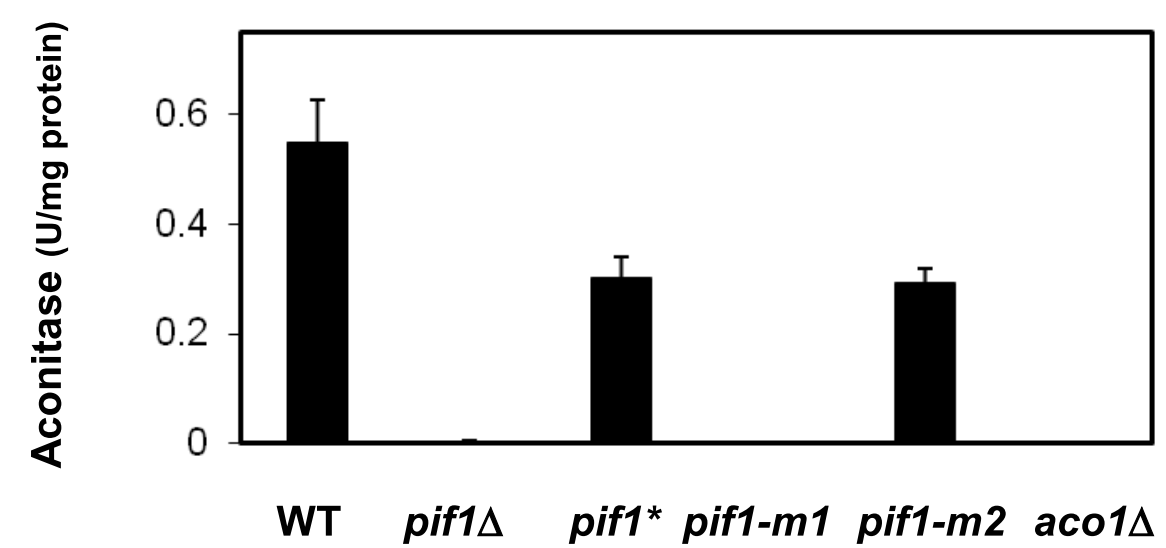

C

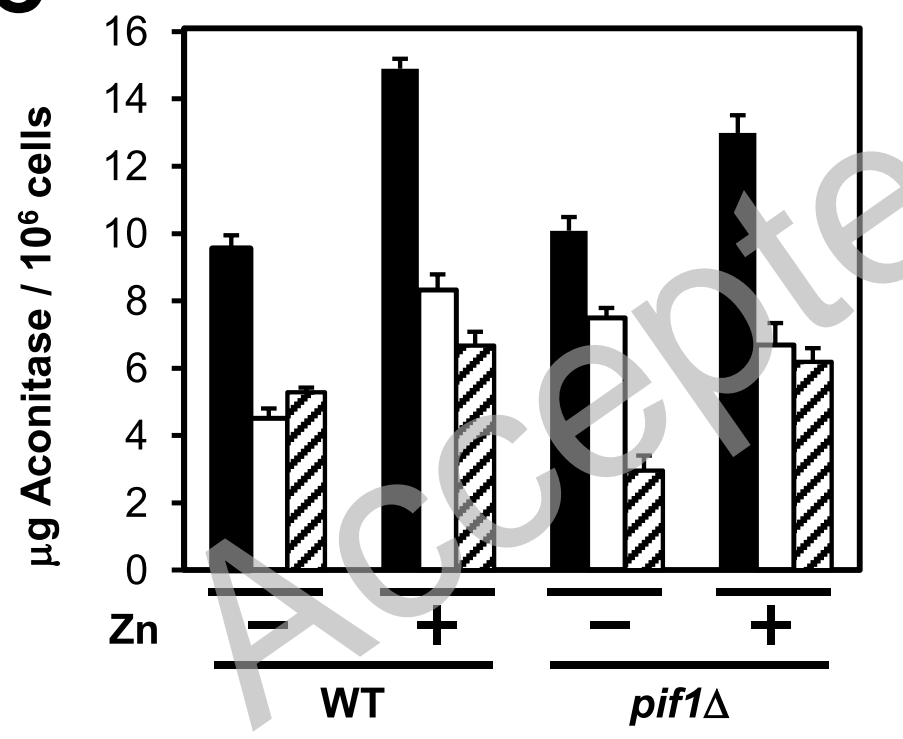

B

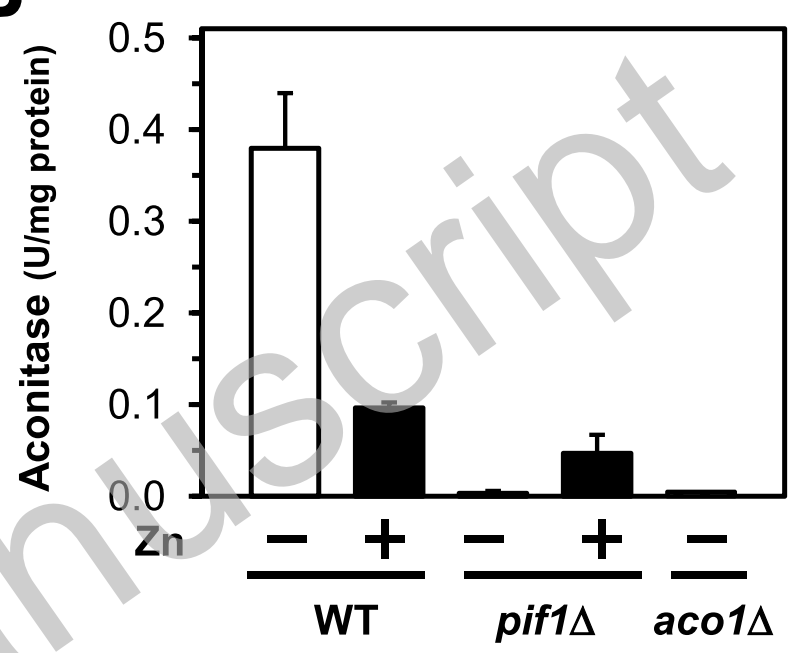

D

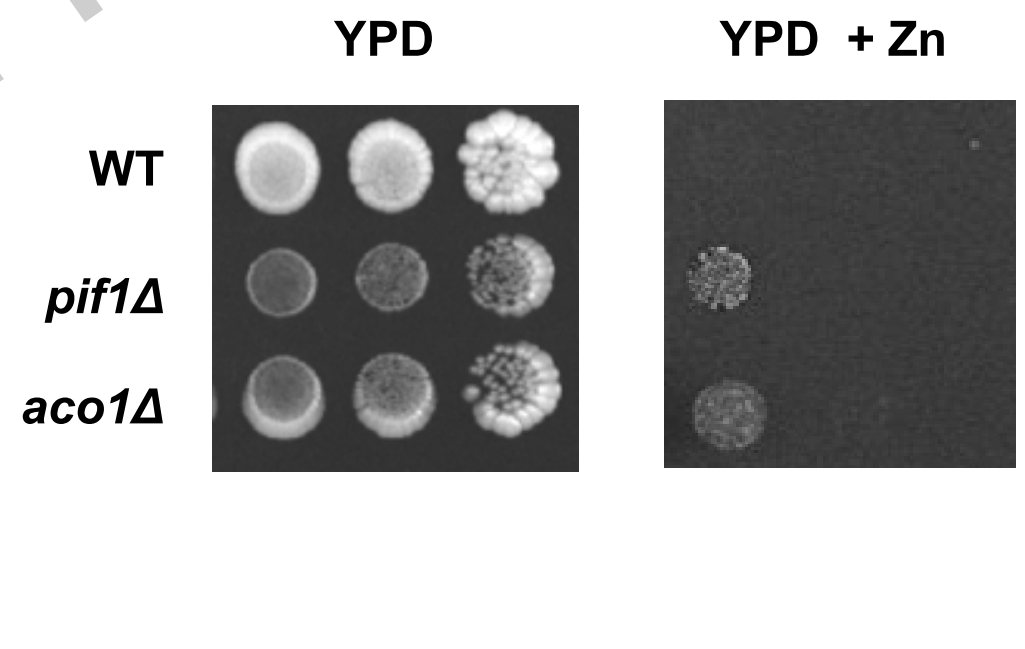

Figure 8. Guirola et al. 